\title{
Evaluating the horizontal alignment of safety management activities through cross-reference of data from safety audits, meetings and investigations
}

\section{Author(s)}

Karanikas, Nektarios

DOI

10.1016/j.ssci.2017.05.008

\section{Publication date}

2017

\section{Document Version}

Proof

\section{Published in}

Safety Science

\section{Link to publication}

\section{Citation for published version (APA):}

Karanikas, N. (2017). Evaluating the horizontal alignment of safety management activities through cross-reference of data from safety audits, meetings and investigations. Safety Science, 98, 37-49.

https://doi.org/10.1016/j.ssci.2017.05.008 
Post-print version: http://dx.doi.org/10.1016/j.ssci.2017.05.008

Evaluating the Horizontal Alignment of Safety Management Activities Through Crossreference of Data from Safety Audits, Meetings and Investigations

\section{Research Paper}

Author and Corresponding Author: Nektarios Karanikas

\section{University:}

Amsterdam University of Applied Sciences

Faculty of Technology / Aviation Academy

Author Address: Weesperzijde 190, 1097 DZ Amsterdam, Netherlands

Personal Email: n.karanikas@hva.nl

Phone number: +31621156287 


\section{Evaluating the Horizontal Alignment of Safety Management Activities Through Cross-reference of Data from Safety Audits, Meetings and Investigations \\ Research Paper}

\section{Abstract}

Vertical and horizontal alignment within organizations are seen as prerequisites for meeting strategic objectives and indications of effective management. In the area of safety management, the concept of vertical alignment has been followed through the introduction of hierarchical structures and bidirectional communication, but horizontal alignment has been given little attention. The principal goal of this study was the assessment of horizontal alignment within an aviation organization with the use of data from safety investigations, audits and meetings in order to explore the extent to which (1) causal factors recorded in safety investigation reports comprised topics discussed by safety committees and focus areas of internal safety auditors, and (2) the agendas of safety committees include weak points revealed during safety audits. The study employed qualitative and quantitative analysis of data collected over a 6 years' period at three organizational levels. The results suggested a low horizontal alignment across the three pairs of the corresponding safety management activities within each organizational level. The findings were attributed to the inadequacy of procedures and lack of a safety information database for consistently sharing safety information, cultural factors and lack of planning for the coordination of safety management activities. The current research comprises a contribution to the literature and practice and introduces a technique to assess the intra-alignment of safety management initiatives within various organizational levels. Future research is needed in order to 
investigate the association between horizontal alignment of safety management practices and safety performance.

Keywords: safety investigations; safety meetings; safety audits; safety management

\section{Introduction}

Safety focused organizations such as aviation enterprises use rates of adverse events (e.g., accident and incident rates) as indicators of their safety performance. However, safety management is not exclusively a damage control policy; organizations must not consider success of their safety initiatives only by avoiding accidents or serious incidents (ILO, 2001). Amongst the various safety management activities, safety audits and review meetings comprise correspondingly fundamental components of safety assurance and planning. The former focus on uncovering organizational deficiencies that might jeopardize safety and contribute to accidents if not timely and effectively managed. Safety review meetings (or simply, safety meetings) emphasize on the improvement of safety levels based on information from various sources (e.g., risk registry, accident and audit reports, external and internal benchmarking, regulatory requirements).

As Leveson (2011) argued, establishment of effectively controlled loops across the hierarchical levels of socio-technical systems and exchange of information amongst actors of same and different levels constitute crucial requirements for achieving organizational objectives and avoiding degraded safety performance. The continuous interaction and coordination amongst the fundamental organizational functions of planning, operating and monitoring across all organizational levels, as well as their alignment with each other, constitute an example of a Critical Success Factor (CSF) that reflects an effective management (Karanikas, 2014a). Similarly, when considering 
safety management, an alignment amongst the frequencies of safety issues discussed in review meetings (i.e. planning function), identified through internal safety audits (i.e. monitoring function) and discovered by safety investigators (i.e. realization of safety management at the operational level) mirrors a common safety focus across an organization and indicates effective implementation of a safety management scheme. The aforementioned views are aligned with the concept and value of vertical and horizontal alignment within organizations discussed in academia and professional practice (e.g., Heesen, 2012; Salimian, Khalili, Nazemi, \& Alborzi, 2012; Simons, 2014).

To date, research initiatives have not explicitly addressed the alignment amongst safety management practices, such an alignment indicating a proportional focus of an organization on respective safety issues. The objective of this study was to assess the degree of horizontal alignment between safety investigations, review meetings and internal audits at three organizational levels of a large aviation organization. The underlying concept of the study was that safety management's common focus at each organizational level is demonstrated when different safety management actors share the same picture of safety issues within those levels and effectively coordinate their actions in order to manage the factors potentially threatening organizational integrity.

The data used in the study corresponded to a period of 6 years and regarded three levels (i.e. operations, middle management and senior management) of the organization under study in order to enable respective comparisons. The results of the analysis showed differences in the emphasis given by safety audits and review meetings with reference to the frequencies of accident and incident factors stated in safety 
investigation reports, as well as a divergence between the topics included in the agendas of safety meetings and the issues uncovered during audits. Follow-up interviews with safety professionals of the organization attributed the findings to the lack of consistent procedures, poor intra-departmental communication and a missing safety information database, along with a culture pointing more on flaws at the operational level and excluding middle and senior organizational functions from internal evaluations. Those factors had collectively led to a misalignment of safety management activities within each organizational level.

The current study comprises a contribution to the literature and professional practice and introduces a technique that can be used, and possibly extended, by practitioners to evaluate the extent to which safety management practices share the same picture of safety challenges and enact in tandem. Future research is needed in order to explore any linkage between horizontal alignment of safety management activities and safety performance.

\section{Literature Review}

\subsection{Safety Management and Performance}

Concerning the organizational performance in general, Stapenhurst (2009) suggested that the achievement of Critical Success Factors (CSF) must have priority against the realization of Key Performance Indicators (KPI). Goglia, Halford \& Stolzer (2008) viewed performance metrics as the essential way of monitoring and controlling quality of deliverables, thus ensuring that organizations achieve and sustain desired performance levels. Performance indicators are often used as benchmarking references for comparing performance internally, amongst departments, or externally, amongst organizations (Kemp, 2006; Goglia et al., 2008). 
Safety management is defined as the application of policies, processes and measures with the scope to prevent adverse safety-related events during the use of a service or product; safety management focus on either the identification of flaws before those contribute to accidents or the investigation of the latter in order to derive aftermaths and correct deficiencies (ICAO, 2016; HSE, 2013). Various safety metrics have been introduced, widely categorised as leading and lagging. Leading or proactive indicators regard safety management performance, whereas lagging or reactive ones reflect safety outcomes, which comprise commonly used measurements of safety performance (e.g., EASA, 2016; ICAO, 2016; IOGP, 2015).

Examples of reactive safety indicators are the number of adverse events and losses (e.g., accidents and incidents, injuries and fatalities), and the fluctuation of their rates. Level of regulatory compliance, percentage of scheduled inspections and audits completed, and number of voluntary reports submitted and processed annually are some examples of leading indicators referring to safety management performance (e.g., ICAO, 2013). Thus, typically, reactive indicators reflect safety performance of services and products and reflect the visible outcomes of activities at the operational level, whereas proactive indicators correspond to safety planning and monitoring tasks.

Currently, international standards and directives claim that if an organization runs a Safety Management System (SMS) effectively, it is expected to improve its safety performance (e.g., BSI, 2007; ILO, 2001; IAEA, 2006; IOGP, 2014). Although the type of safety management system might affect safety performance (Arocena \& Núñez, 2010), a strong relation between the implementation of a safety management and improved safety performance is yet a proposition to be proved (e.g., Robson, 
Clarke, Cullen, Bielecky, Severin, Bigelow, Irvin, Culyer, \& Mahood, 2007; Thomas, 2012; Kaspers, Karanikas, Roelen, Piric, \& de Boer, 2016a).

Only few older studies have identified moderate linkages of specific safety management activities and generic organizational factors to safety performance. For example, Tam \& Fung (1998) found that post-accident investigations, the level of subcontracted labour, safety awards, and safety training influenced positively safety performance in the construction industry, whereas safety committees, management involvement and safety orientation were not associated with safety outcomes. Vredenburgh (2002) showed that only hiring practices were predictive of injury rates in hospitals. A research in offshore companies revealed that favourable safety management scores were associated with lower rates of lost time injuries, safety audits playing a major role (Mearns, Whitaker, \& Flin, 2003). The findings of Nga, Chenga, \& Skitmoreb (2005) suggested that safety audits and review meetings scored low in the relative importance of organizational and project-related individual factors on safety performance. A survey of Kaspers, Karanikas, Roelen, Piric, van Aalst \& de Boer (2016b) across aviation companies in the frame of a research about safety metrics revealed few, diverse and occasionally contradictory associations between metrics of SMS processes and safety outcomes.

The variance of findings regarding the relation between safety management and safety performance might be attributed to (1) the different ways SMS processes are implemented and thresholds of safety outcomes are interpreted across companies (Kaspers at al. 2016b), and/or (2) the fact that safety management activities are widely viewed as individual elements and the interconnectivity and interdependency of the respective safety initiatives within organizations are not considered (Karanikas, 2016b). 
The consideration of such interlinks is of paramount importance since continuous interaction and vertical and horizontal communication in an organization play a critical role in its endurance and success (Vredenburgh, 2002; Hofmann, Jacobs, \& Landy, 1995) and the distortion and concealment of significant safety information do not enable a common risk perception (Pidgeon, 1991). As Karanikas (2016a) added, the lack of a shared perception amongst management functions hinders the ability of an organization to align its safety management initiatives, and the vertical distance between management and operations does not allow a common approach to safety.

An analogous concept comprises part of a relatively new safety paradigm named System Theoretic Accident Model and Processes (STAMP), which is grounded on systems engineering (Leveson, 2004). According to the STAMP theory (Leveson, 2011), unwanted events do not occur merely due to failures of individual components, but also because of uncontrolled interactions of system elements, lack of feedback loops across hierarchical levels and ineffective communication amongst actors of same organizational levels. Feedback mechanisms and communication channels update the picture that system controllers obtain about the states and objectives of processes and provide the controllers with the opportunity to adjust the system in order to meet those objectives.

\subsection{Safety Meetings, Audits and Investigations}

\subsubsection{Safety Meetings}

Safety committees comprise a principal form of managers' actual involvement into safety during dedicated review meetings, and they signal management's commitment to safety (Mearns, Whitaker, \& Flin, 2003). As Manuele (2008) and Ferret \& Hughes (2007) stated, safety meetings offer a chance to management to appraise 
broad views on noteworthy safety issues, and safety committees must conclude to interventions in safety management regarding its planning, monitoring and operation.

According to various authors (e.g., Bhagwati, 2006; Channing, 2008a), safety committees are expected to: discuss progress of previous meeting actions; review latest safety statistics and risk assessments; get informed about latest accidents and incidents; discuss accident causes and planned countermeasures; comment on safety visits and audit observations; support safety rules' development; review new safety regulations and standards; review safety performance; monitor health and safety training; decide on specific safety projects.

\subsubsection{Safety Audits}

Safety audits comprise a fundamental proactive mechanism for providing feedback to safety professionals and operations' staff in regard to deficiencies in the implementation of a safety management scheme. The goal of safety audits, either internal or external, is to identify positive and negative aspects of how safety is managed across an organization (e.g., FAA, 2006; Channing, 2008b). Although audits have been traditionally focused on compliance checks, a transition from a compliancebased to a performance-based assessment of Safety Management Systems (SMS) has been quite recently fostered, especially in the aviation domain (e.g., ICAO, 2013; EASA, 2014). This initiative indicates that authorities, in addition to compliance with standards, are interested in the effective SMS implementation.

Manuele (2008) pointed that audits aim to reveal shortcomings in safety management's operationalization, change of management, risk assessment, procurement practices and control hierarchy. Internal safety audits are part of a 
proactive safety assurance, and, ideally, should apply to all levels of the organization under audit (Ruud, 2003; IIA, 2009; IIA, 2012).

\subsubsection{Safety Investigations}

Safety investigations are a reactive method of safety assurance. The aim of accident and incident investigations is to explore factors that contributed to adverse events, identify latent or visible deficiencies and prevent future accidents by recommending measures for hazards' elimination or mitigation (e.g., ICAO, 2013; Bhagwati, 2006; Della-Giustina, 2007; Ferret \& Hughes, 2007; Hughes \& Hughes, 2008; Ridley 2008).

Accidents have direct implications in terms of fatalities, injuries, labour and material costs, and indirect consequences such as loss of market share, legal disputes, and a decrease of employees' morale. Therefore, the rates of adverse events and the results of accident investigations have been of high interest for all stakeholders (i.e. companies, industry sectors, authorities and the public), and the analysis of accident data in terms of frequencies of events and causes have become the main indicator of safety performance (e.g., IATA, 2014; ICAO 2016; IAEA, 2015; IOGP, 2014). Safety policy and procedures, risk registry, safety training and the rest of the safety management activities might be updated as result of the information included in safety investigation reports.

\subsection{Alignment of Safety Management Activities}

The literature cited in section 2.2 above suggests that safety meetings, audits and investigations are valuable means for collecting and sharing information about safety management and safety performance, as well as planning for appropriate interventions. The aforementioned safety management activities correspond to the three 
organizational pillars discussed by Karanikas (2014a): "Planning" (i.e. safety committees), "Checking" (i.e. safety assurance in the form of audits) and "Operations" (i.e. problems identified at the operational level during safety investigations), which are expected to be continuously aligned and harmonized. Hanson, Melnyk and Calantone (2011) suggested that operational alignment within an organization is influenced by factors such as understanding, acceptance, standards, incentives and formal alignment, the latter including linkage and consistency. However, as Heesen (2012) noticed, directions, rules and controls might be effective for achieving a vertical alignment, but they do not suffice when pursuing horizontal alignment; the latter necessitates the consideration of shared values and objectives, norms and performance incentives: “An efficient horizontal coordination can often not be directed from above as it requires an insight into the details of the process organization, which is mainly developed by those directly executing the tasks" (Heesen, 2012, pp.8).

Various studies on the linkage between organizational alignment and performance showed that high internal structure fit (i.e. the differentiation - integration relation within a company) was associated with increased profitability (Powell, 1992), alignment as part of organizational ambidexterity at a business-unit level was positively correlated with organizational performance (Gibson \& Birkinshaw, 2004), a statistically significant relation was found between vertical alignment of business managers with line managers and performance of a manufacturing unit (Joshi, Kathuria, \& Porth, 2003), and a positive association was detected between vertical strategic alignment within organizations and public service performance (Andrews, Boyne, Meier, O'Toole, \& Walker, 2012). However, the performance measurements used in the aforementioned studies excluded safety and focused on other types of business performance metrics such as finance, productivity and customer satisfaction. As 
Kathuria, Joshi, \& Porth (2007) concluded in their respective literature review, vertical alignment has attracted considerably more attention of researchers compared to the concept of horizontal alignment.

According to the literature cited in section 2.1 above, solely exploring the effects of individual practices on safety does not suffice to evaluate safety management. Rather, there is a need to address the coordination and interlinks of safety management activities as a vital step for ensuring that those are properly aligned and commonly aware of the factors affecting safety in an organization, so to enable joint efforts for controlling those factors. Hence, since an alignment-focused, horizontally-harmonized approach to safety management is required and the significant contribution of safety investigation, audits and meetings to a successful safety management has been recognised, it can be argued that: (1) data from safety investigations must constitute areas of interest for safety meetings and internal audits, and (2) findings from safety audits must comprise agenda items of safety meetings. Such a common focus on factors influencing safety would indicate a mature safety management system with its core activities properly coordinated and horizontally aligned.

\section{Methodology}

\subsection{Research Framework}

The substantial implementation of a safety management system is broadly achieved through the collection and analysis of both quantitative and qualitative data. Instruments such as the Effectiveness of Safety Management (Eurocontrol, 2012) and the SMS evaluation tool (SMICG, 2012) suggest the assessment of SMS characteristics and maturity level correspondingly by using a variety of qualitative and quantitative data. Karanikas (2014b) proposed various qualitative and quantitative methods for 
evaluating the effective implementation of SMS in terms of its planning, operation and monitoring, and demonstrated the merit of combining those methods in the assessment of safety management (Karanikas, 2016b).

The current study combined qualitative and quantitative analysis of data from safety investigation reports, safety meeting minutes and internal safety audit reports of a large aviation organization over a six (6) years' period. The organization operates in southern Europe, employees about 18.000 personnel and is divided into three sections representing middle-level management [hereafter referred as section(s)], each one conducting flights from its subordinate operating units [hereafter referred as unit(s)] and providing ground services and maintenance support.

The main goal of the study was to assess the degree to which safety meetings and internal audits were aligned between them and with the actual safety issues the aviation organization faced, and explore the underlying reasons. The accident and incident investigation reports comprised the basis for assessing the degree of common focus amongst the operationalization of safety (i.e. management of local and systemic flaws), planning/improvement activities (i.e. safety committee meetings) and monitoring practices (i.e. internal safety audits). An intra-alignment of the aforesaid safety management activities would be claimed if the deficiencies identified through safety investigations would be discussed during safety meetings and addressed by safety auditors at a similar extent, and findings of safety audits would be analogically attended during safety meetings. This would indicate adequate coordination, interaction and effective communication amongst safety management actors. Under the aforementioned concept, the overarching analysis question linked to the scope of the 
research was "To what degree do safety committees and auditors are aligned with each other and with the results from safety investigations?”.

Internal safety audits at the units of the specific organization are performed every 18 months by staff positioned at the headquarters level (hereafter also referred as organization level) and every 12 months by staff of the corresponding section, the latter representing middle level management. Safety auditors are qualified personnel with solid operational experience who have undergone a respective 3-days training. Safety audits at each unit last 1-3 days based on unit's size and operational complexity.

A guidebook is used for all audits; it is divided into parts corresponding to the various areas (e.g., safety, security, quality) and activities of each unit (e.g., flight operations, maintenance, ground services). The guidebook includes a list of about 260 safety audit topics based on the rules, standards, directives and procedures that apply to each activity type. The main focus of audits is compliance and identification of strong and weak points; however, the auditors are prompted to explore the reasons for each case of incompliance and trace the actions the unit, section and organization have taken in order to tackle identified flaws.

Safety meetings are held at all functional levels with different periodicity: once annually at the organization and section levels and quarterly by each unit. Each level might call for additional safety meetings when major local or organizational changes are planned or other special reasons emerge. The agenda and participants of safety meetings at the unit level are outlined in a respective safety handbook of the organization, whereas the discussion topics of safety meetings at the organization and section levels are not described in a relevant documentation. In the latter cases, the agenda is compiled based on participants' proposals collected prior to each meeting. 
During the safety meetings at the units the following topics are discussed: amount of flight and ground activities, safety awards to unit's staff, findings and remedies stated in safety investigation reports published by the organization, recent safety occurrences at the unit, topics of interest referred in safety meeting minutes held by other units, and progress of decisions made during former safety meetings. Participants might suggest additional agenda items prior to each meeting.

The safety meeting minutes are circulated amongst participants prior to their publication. This practice ensures consensus and minimizes any misinterpretation of the statements made by safety committee members. The duration of safety meetings conducted at every organizational level is not limited, although a respective time schedule is included in the agendas. Practically, the discussions held during such meetings are not affected by time restrictions and all safety issues can be raised and thoroughly addressed by the safety committee members.

\subsection{Sample}

The sample size of the research was affected by limitations of data in terms of availability, accessibility and format. However, the 6-years period was deemed adequate to reduce potential variations in the fidelity of auditors and minute authors. Also, the exploration of data over such a period would compensate for possible lags amongst the aforementioned safety management activities. Certainly, time is required in order to communicate the results of safety investigations and internal audits to all levels and staff of an organization, in order for them to respond accordingly. However, the time frame of such delays is usually short (i.e. few days or weeks), thus these were contemplated as negligible compared to the 6-years' time sampled. 
The datasets included in the study are presented in Table 1 . In addition to the records regarding the organization in overall, data was collected from one representative unit, which is staffed with about 1200 employees, and the section to which the specific unit reports. This way the researcher explored the horizontal alignment amongst safety management activities at the strategic, tactical and operational levels (i.e. organization, section \& unit correspondingly). In order to interpret the analysis results, the findings were discussed with four safety professionals of the headquarters' safety department (2 safety auditors and 2 persons assigned with the preparation of safety meetings) in the form of unstructured interviews individually scheduled with each interviewee.

\begin{tabular}{|l|c|c|c|}
\hline \multirow{2}{*}{ Data sources } & \multicolumn{3}{|c|}{ Functional Level } \\
\cline { 2 - 4 } & $\begin{array}{c}\text { STRATEGIC- } \\
\text { ORGANIZATION } \\
\text { (all units included) }\end{array}$ & $\begin{array}{c}\text { TACTICAL- } \\
\text { SECTION } \\
\text { (all subordinate } \\
\text { units included) }\end{array}$ & $\begin{array}{c}\text { OPERATIONAL- } \\
\text { UNIT }\end{array}$ \\
\hline $\begin{array}{l}\text { Safety } \\
\text { investigation } \\
\text { reports } \\
\begin{array}{l}\text { lall investigated } \\
\text { (serious) incidents } \\
\text { and accidents) }\end{array}\end{array}$ & 342 & 176 & 18 \\
\hline $\begin{array}{l}\text { Safety meeting } \\
\text { minutes audit }\end{array}$ & 9 & 6 & 20 \\
\hline $\begin{array}{l}\text { Safety } \\
\text { reports }\end{array}$ & 39 & 21 & 3 \\
\hline
\end{tabular}

Table 1: Data Sets Included in the Research

\subsection{Cross-reference of Data}

The data from safety investigation reports, meeting minutes and internal audit reports were used in pairs for assessing the extent of alignment amongst the respective safety management activities. Table 2 presents the pairs of data sources used to answer each of the analysis sub-questions which collectively addressed the overarching question and are presented in the $3^{\text {rd }}$ column of the specific Table. 


\begin{tabular}{|c|c|l|}
\hline $\begin{array}{c}\text { Overarching question: To what degree do safety committees and auditors are } \\
\text { aligned with each other and with the results from safety investigations? }\end{array}$ \\
\hline \multicolumn{2}{|c|}{ Pairs of Safety Data Sources } & \multicolumn{1}{c|}{ Analysis Questions } \\
\hline $\begin{array}{c}\text { Investigation } \\
\text { reports }\end{array}$ & Audit reports & $\begin{array}{l}\text { Have safety auditors revealed problems } \\
\text { at the same frequency such problems } \\
\text { were recorded in the safety } \\
\text { investigation reports? }\end{array}$ \\
\hline Audit reports & Meeting minutes & $\begin{array}{l}\text { Have safety committees proportionally } \\
\text { discussed internal safety audit } \\
\text { findings? }\end{array}$ \\
\hline $\begin{array}{c}\text { Investigation } \\
\text { reports }\end{array}$ & Meeting minutes & $\begin{array}{l}\text { Have safety committees attended } \\
\text { causal factors at the same extent such } \\
\text { factors were uncovered through safety } \\
\text { investigations? }\end{array}$ \\
\hline
\end{tabular}

Table 2: Pairs of Safety Data Sources and Corresponding Analysis Questions

Content analysis was performed in order to code the data from safety investigation reports, meeting minutes and internal audit reports, as presented hereafter for each data source. The content analysis was based on the taxonomy of Table 3, which the organization uses for the classification of accident and incident causal factors. The factors "No cause identified" and "Other factor" where not included in the study due to their abstract nature and the inability to link them to topics discussed by safety committees and raised by safety auditors. The coding was conducted and crossreferenced by the researcher and an experienced safety professional in order to ensure an adequate level of inter-rater reliability $(>75 \%)$ calculated through the Intra-Class Correlations function of the SPSS 22 software (IBM, 2013).

In order to answer the analysis questions formulated in Table 2, comparisons were made amongst the ratios of causal factors stated in the investigation reports, recorded in the safety meeting minutes and included in the internal safety audit reports. The comparisons regarded the organization in overall and the representative section and unit and were performed per year and in total for the whole sample. Since different ratios of accident and incident factors were calculated per audit and meeting report, the 
average values of such ratios were considered per year and the whole dataset for each organizational level. The processing steps for each dataset are elaborated in the following paragraphs.

\subsubsection{Safety Investigation Reports}

The causal factors stated in the safety investigation reports were recorded and ratios were calculated (i.e. overall count of each factor divided by the number of accidents) for the whole organization and for the section and the unit under consideration in total and per year. Example given, if the Bird Strike factor had contributed to 40 out of the 342 accidents/incidents of the organization, the ratio was calculated as $40 / 342=0.117$.

\subsubsection{Safety Meeting Minutes}

The content analysis of the safety meeting minutes resulted to frequencies of accident and incident causal factors discussed per meeting; the calculation of frequencies of other meeting topics were outside the scope of the study. Afterwards, the researcher calculated the ratio of each causal factor discussed during safety meetings per total agenda topics referred to accident and incident factors. For example, if two (2) topics of a safety meeting were related to the Foreign Object Debris (FOD) factor and the minutes included in total five (5) topics about causal factors of safety events, the ratio calculated was $2 / 5=0.4$. After the specific task was completed for each document, the average values of the ratios per causal factor was calculated for the safety meeting minutes published by the organization, section and unit per year and in total.

\subsubsection{Safety Audit Reports}

Content analysis and ratio calculations were conducted for the safety audit reports at the organization, section and unit levels, as followed in the analysis of safety 
meeting minutes. However, only the FOD, Bird Strikes, Aircrew and Maintenance Personnel Unsafe Acts and Material Failures factors were considered, because, according to the organization's audit handbook, the rest three factors of Table 3 (i.e. Supervision, Domestic Object Debris and Depot Maintenance Act) are not assessed during internal safety audits. Table 3 includes also indicative areas per causal factor that auditors were checking according to the respective handbook.

\begin{tabular}{|l|l|}
\hline \multicolumn{1}{|c|}{ Taxonomy of Causal Factors } & \multicolumn{1}{c|}{ Example audit checks } \\
\hline Aircrew act & $\begin{array}{l}\text { Type and validity of licence held; on job } \\
\text { performance; knowledge of procedures; } \\
\text { application of skill assessment } \\
\text { procedures. }\end{array}$ \\
\hline Bird strike & $\begin{array}{l}\text { Bird population in the airfield; height and } \\
\text { types of flora in the airport; means to } \\
\text { deter or dislodge birds. }\end{array}$ \\
\hline Domestic Object Debris (DOD) & (not included in the audit handbook) \\
\hline Foreign Object Debris (FOD) & $\begin{array}{l}\text { Condition of taxi ways, runways and } \\
\text { aircraft parking areas; tool control by } \\
\text { ground staff; FOD control procedures. }\end{array}$ \\
\hline Maintenance personnel act & $\begin{array}{l}\text { Type and validity of licence held; on job } \\
\text { performance; knowledge of procedures; } \\
\text { procedures for periodic evaluation of } \\
\text { skills; logs keeping. }\end{array}$ \\
\hline Material failure & $\begin{array}{l}\text { Warehouse conditions; check/acceptance } \\
\text { procedures for new or repaired material; } \\
\text { transportation means. }\end{array}$ \\
\hline No cause identified & (not included in the study) \\
\hline Other factors (e.g. weather) & (not included in the study) \\
\hline Outsource-depot maintenance act & (not included in the audit handbook) \\
\hline Supervision & not included in the audit handbook) \\
\hline
\end{tabular}

Table 3: Causal Factors Taxonomy and Indicative Audit Checks (alphabetical order)

\section{Results}

\subsection{Organization}

The causal factor ratios per data source type for the organization in overall are presented in Table 4 and illustrated in Figure 1; the respective data per year are reported in the Appendix. The overall results show that although all factors had more or less 
frequently contributed to accidents and (serious) incidents, safety audits revealed flaws mainly for the Foreign Object Debris (FOD) factor, while supervision issues were discussed most frequently during safety meetings. More specifically:

- Aircrew acts were a topic of meetings at a degree analogous to their contribution to safety events, but no respective findings were recorded during audits.

- The Bird Strike and Depot Maintenance factors seemed proportionally addressed by the respective safety management activities.

- The FOD related issues were quite frequently addressed during safety audits, whereas they contributed to safety events at a lower degree and were included sporadically in the agenda of the review meetings.

- The Supervision factor was discussed more often during safety meetings than found in the investigation reports.

- Material failures were often recorded in the investigation reports but rarely discussed during meetings and tackled during safety audits.

- Problems related to DOD were not included in the agendas of safety meetings although DOD was a causal factor for $10 \%$ of the investigated events.

\begin{tabular}{|l|c|c|c|}
\hline \multirow{2}{*}{ Causal Factors } & \multicolumn{3}{|c|}{ Safety data source } \\
\cline { 2 - 4 } & $\begin{array}{c}\text { Investigation } \\
\text { reports }\end{array}$ & $\begin{array}{c}\text { Audit } \\
\text { reports }\end{array}$ & $\begin{array}{c}\text { Meeting } \\
\text { minutes }\end{array}$ \\
\cline { 2 - 4 } & (ratios) & \multicolumn{2}{c|}{ (average values of ratios) } \\
\hline Aircrew act & 0.22 & 0.00 & 0.17 \\
\hline Bird strike & 0.09 & 0.14 & 0.10 \\
\hline Domestic Object Debris & 0.10 & $*$ & 0.00 \\
\hline Foreign Object Debris & 0.14 & 0.49 & 0.05 \\
\hline Maintenance personnel act & 0.13 & 0.00 & 0.14 \\
\hline Material failure & 0.44 & 0.01 & 0.02 \\
\hline $\begin{array}{l}\text { Outsource-depot } \\
\text { maintenance act }\end{array}$ & 0.07 & $*$ & 0.02 \\
\hline Supervision factors & 0.12 & $*$ & 0.50 \\
\hline * Not assessed during safety audits & & \\
\hline
\end{tabular}


Table 4: Ratios of Causal Factors per Data Source Type for the Organization

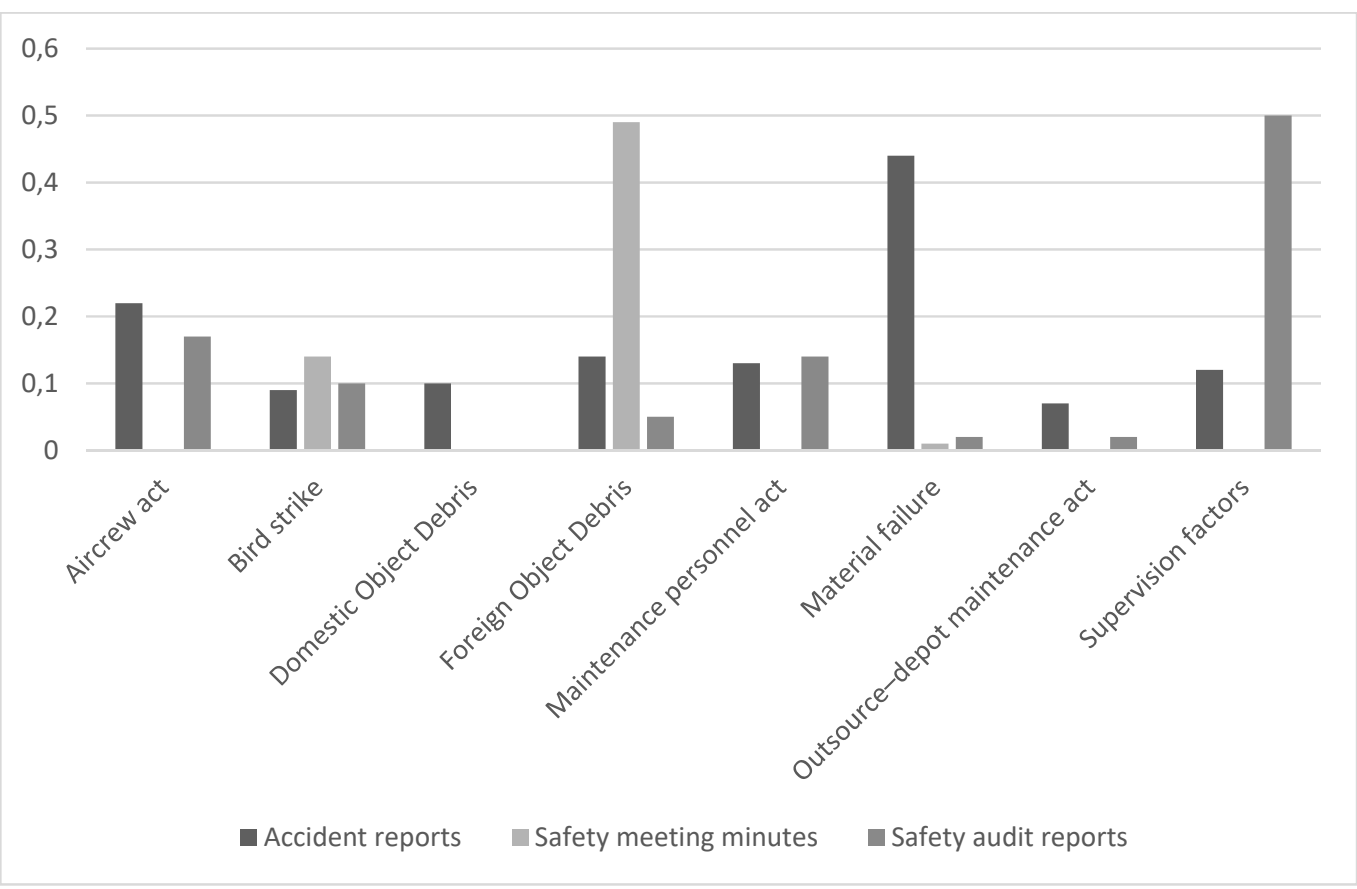

Figure 1: Comparison of Causal Factor Ratios per Data Source Type for the Organization

The following observations for each causal factor were made regarding their average ratios per year (Table A.1 of Appendix):

- In Year 1 the Aircrew act factor was discussed in meetings at about the same extent it was stated in the investigation reports. Almost no attention was given to the specific cause until Year 6 when it became a principal discussion topic. Audit reports did not include any finding related to this causal factor.

- Audits in Years 1, 2 \& 6 emphasized on weaknesses related to bird strikes at a higher degree the specific factor was stated in investigation reports, but in Years 3 to 5 there was little or no emphasis. The specific cause entered safety meetings as an agenda topic in Year 3, where it was extensively discussed, and in Year 4, but it disappeared in Year 5. In Year 6, respective ratios were quite similar. 
- DOD, Depot maintenance and Material failure problems were not actually discussed in safety meetings over all 6 years. Problems related to the latter factor were not recorded in any audit report published in this period.

- Over time, the FOD factor was found in audit reports much more frequently than it contributed to safety events, whereas it was almost never discussed during safety meetings.

- Maintenance personnel acts were not addressed in the findings of audit reports of any year. They were periodically part of meeting agendas in 3 out of the 6 years with a different gravity than this factor was stated in investigation reports.

- Supervision related deficiencies were tackled in safety reviews of 4 out of the 6 years with usually higher frequencies than the particular factor was found in investigation reports.

\subsection{Section}

Table 5 and Figure 2 present the results at the section level regarding the whole sample; Table A.2 in the Appendix includes the results for each year of study. The overall results uncovered that, although all factors had played a role into occurrences at this functional level, safety auditors principally referred to deficiencies for the FOD and DOD factors, and safety committees addressed 6 out of the 8 causal factors. Particularly:

- The Aircrew acts, Depot maintenance and Supervision factors were attended in meetings at an extent analogue to their contribution into the safety events. Auditors never reported any finding about the Aircrew acts factor.

- The Bird Strike factor was addressed in the safety meeting minutes and audit reports more frequently than it contributed to accidents and (serious) incidents. 
- DOD issues were recorded in $14 \%$ of the safety events but never discussed during meetings.

- The FOD cause was a topic of meetings at a ratio close to its respective contribution to events, but it had been overemphasized during audits.

- The meeting participants focused on the unsafe acts of maintenance personnel more than this factor played a role into safety events, whereas no relevant audit findings were reported.

- Although material failures affected about half of the safety events, this cause was not proportionally discussed in safety meetings and no respective findings were recorded in audit reports.

\begin{tabular}{|l|c|c|c|}
\hline \multirow{2}{*}{ Causal Factors } & \multicolumn{3}{|c|}{ Safety data source } \\
\cline { 2 - 4 } & $\begin{array}{c}\text { Investigation } \\
\text { reports }\end{array}$ & $\begin{array}{c}\text { Audit } \\
\text { reports }\end{array}$ & $\begin{array}{c}\text { Meeting } \\
\text { minutes }\end{array}$ \\
\cline { 2 - 4 } (ratios) & (average values of ratios) \\
\hline Aircrew act & 0.16 & 0.00 & 0.13 \\
\hline Bird strike & 0.11 & 0.21 & 0.29 \\
\hline Domestic Object Debris & 0.14 & $*$ & 0.00 \\
\hline Foreign Object Debris & 0.14 & 0.48 & 0.18 \\
\hline Maintenance personnel act & 0.12 & 0.00 & 0.21 \\
\hline Material failure & 0.49 & 0.02 & 0.12 \\
\hline $\begin{array}{l}\text { Outsource-depot } \\
\text { maintenance act }\end{array}$ & 0.04 & $*$ & 0.00 \\
\hline Supervision factors & 0.11 & $*$ & 0.08 \\
\hline$*$ Not assessed during safety audits & \multicolumn{4}{|l}{} \\
\hline
\end{tabular}

Table 5: Ratios of Causal Factors per Data Source Type at the Section Level 


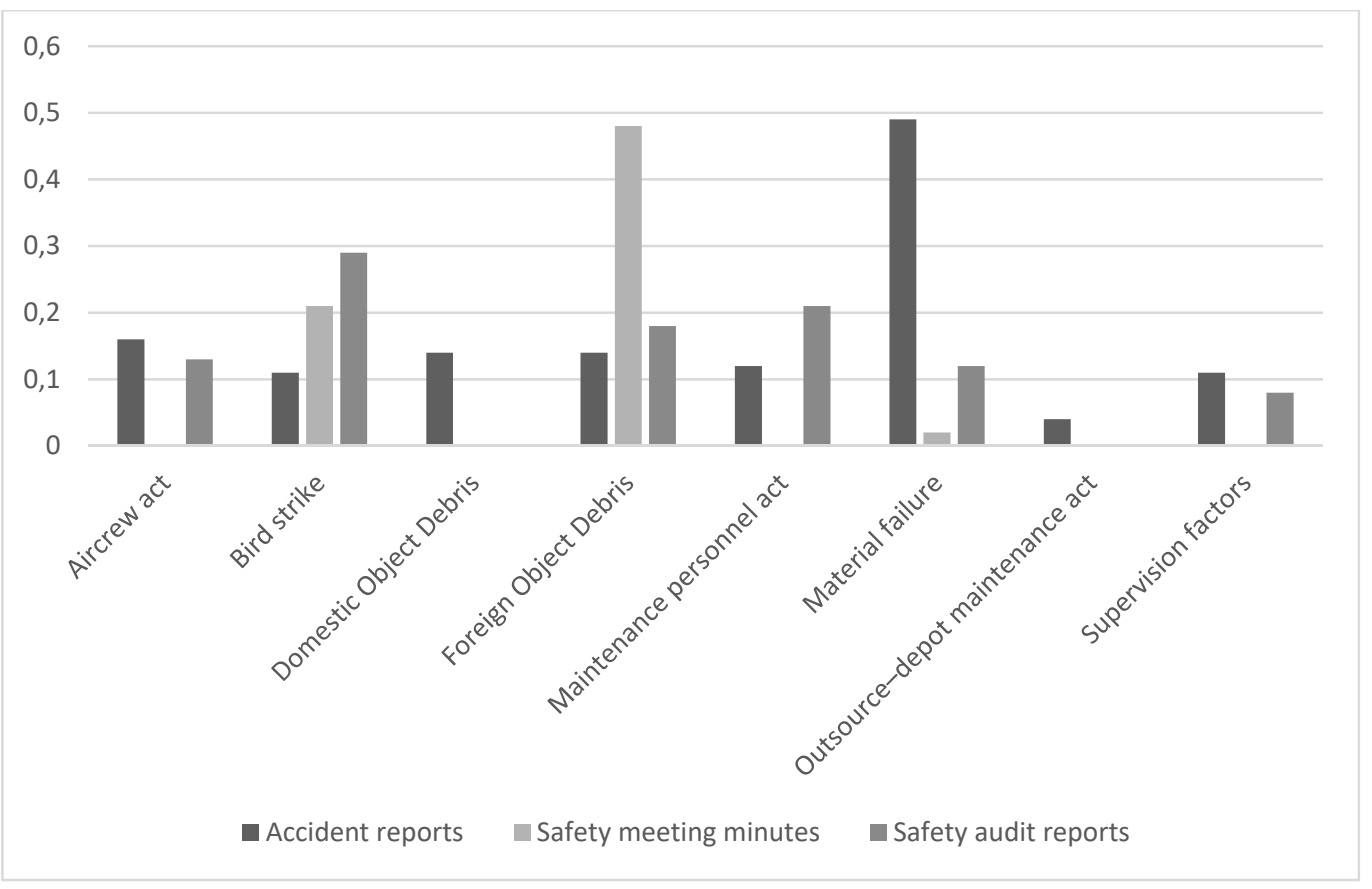

Figure 2: Comparison of Causal Factor Ratios per Data Source Type at the Section Level

In regard to the variations of ratios of causal factors over time (Table A.2 of Appendix):

- In Years 1 to 5, the Aircrew acts factor was occasionally discussed in safety meetings with a higher frequency than found in investigation reports. The ratios this cause was recorded in meetings minutes and investigations reports were equal in Year 6. Audit reports did not include any relevant finding.

- Bird Strikes entered the review meetings agendas as a discussion item the last 3 years of the sample, while respective flaws were decreasingly spotted by auditors over Years 1 to 5. Quite similar ratios were observed in Year 6.

- DOD and Depot maintenance factors were never discussed in safety meetings.

- The FOD cause was almost always tackled by auditors with a considerably higher frequency than it caused (serious) incidents and accidents; the specific factor was 
absent from meeting minutes in 3 out of the 6 years. The ratios were very similar in Year 1 and relatively akin in Year 6.

- Auditors never stated a finding for the Maintenance personnel acts factor and meeting participants emphasized much on it only in 2 out of the 6 years.

- Findings relevant to material failures were almost never revealed from audits. The aforesaid cause was discussed in the meetings of 2 out of the 6 years but with a lower proportion that it contributed to safety events of the respective years.

- Safety meetings addressed the Supervision factor in 2 out of the 6 years but with a much higher frequency than the specific cause had been found in the investigation reports of the respective years.

\subsection{Unit}

The accident factor ratios per data source type for the unit under study are presented in Table 6 and illustrated in Figure 3 for the whole sample as well as per year in the Table A.3 of the Appendix. According to the results, although all factors contributed to the safety events of the specific unit, safety audit findings referred mostly to the Bird Strike factor followed by the FOD problems, and 2 out of 8 causes were not discussed during safety meetings. More specifically:

- Supervision problems were found at about the same frequency in safety investigation reports and meeting minutes.

- The Aircrew Act factor was quite under-addressed by the unit's safety committee compared to its contribution to accidents and (serious) incidents. Auditors did not record any relevant flaws. 
- Bird Strike problems were a topic of meetings at about the same extent this factor was involved into safety events. This cause was given extremely high attention during audits.

- DOD and Depot maintenance issues were not discussed during safety reviews, but they had contributed little to safety occurrences compared to the rest of the causal factors.

- The FOD factor was more frequently discussed in safety meetings and found in audit reports than stated in investigation reports.

- Each of the Maintenance personnel acts and Material failures factors contributed to $28 \%$ of the safety events but no relevant findings were reported by auditors. Safety meetings participants addressed the aforesaid factors with a relatively low level of attention.

\begin{tabular}{|l|c|c|c|}
\hline \multirow{2}{*}{ Causal Factors } & \multicolumn{3}{|c|}{ Safety data source } \\
\cline { 2 - 4 } & $\begin{array}{c}\text { Investigation } \\
\text { reports }\end{array}$ & $\begin{array}{c}\text { Audit } \\
\text { reports }\end{array}$ & $\begin{array}{c}\text { Meeting } \\
\text { minutes }\end{array}$ \\
\cline { 2 - 4 } Aircrew act & (ratios) & 0.00 & 0.18 \\
\hline Bird strike & 0.39 & 0.67 & 0.07 \\
\hline Domestic Object Debris & 0.11 & $*$ & 0.00 \\
\hline Foreign Object Debris & 0.06 & 0.33 & 0.24 \\
\hline Maintenance personnel act & 0.11 & 0.00 & 0.10 \\
\hline Material failure & 0.28 & 0.00 & 0.06 \\
\hline $\begin{array}{l}\text { Outsource-depot } \\
\text { maintenance act }\end{array}$ & 0.28 & $*$ & 0.00 \\
\hline Supervision factors & 0.06 & $*$ & 0.30 \\
\hline$*$ Not assessed during safety audits & 0.28 & \multicolumn{4}{|l}{} \\
\hline
\end{tabular}

Table 6: Ratios of Causal Factors per Data Source Type at the Unit Level 


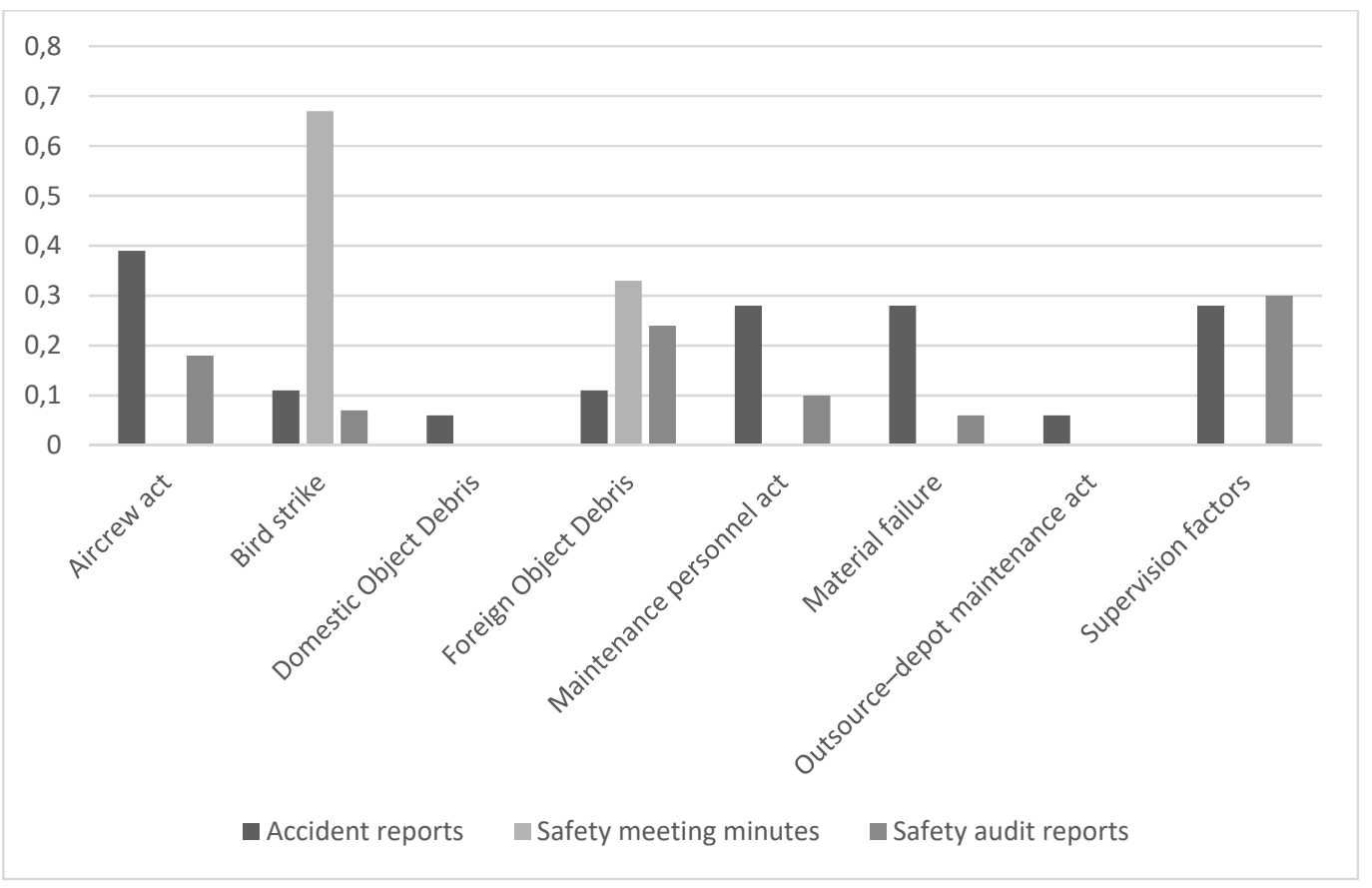

Figure 3: Comparison of Causal Factor Ratios per Data Source Type at the Unit Level

In regard to the ratios recorded over the period of 6 years per causal factor (Table A.3 of Appendix):

- The Aircrew acts factor was discussed in safety meeting only after Year 3; a consistent similarity to the ratios of findings from investigations was observed in Years $4 \& 5$. Audit reports did not include any relevant flaw.

- Although Bird strikes did not contribute to any (serious) incident or accident over the 6 years studied, auditors focused much on related flaws in Years 1 and 6 . The specific cause was sporadically discussed in meetings with a higher emphasis during Year 6.

- DOD cause appeared only in the investigation reports of Year 3 and was never discussed during safety reviews.

- The FOD cause had always been a topic of the safety meetings agendas, albeit with a frequency not consistent with the extent of its involvement in (serious) incidents 
and accidents. Audit reports included the FOD factor in the lists of findings only in Year 3, with an almost exclusive reference.

- Auditors never stated findings related to Maintenance personnel acts. The particular factor was a topic of safety reviews in 2 out of the 6 years with ratios dissimilar to the ones it was referred in investigation reports.

- Material failures were not a focal point of audits at any year and they were discussed only in the meetings of Year 3. However, the aforementioned cause contributed significantly to the safety events of years $2,3 \& 4$.

\subsection{Interviews}

In order to allow time for preparation and reflection before the individual interviews, the results presented in Tables $4,5 \& 6$ where shared with the participants in advance. The first comment stated by the interviewees was that the outcomes of the analysis were unexpected. In their capacity as safety staff at the senior management level, they were confident that safety management activities of the organization were satisfactorily emphasizing on the same safety problems. The comments collected during the interviews were grouped into three (3) categories: common organizational deficiencies, preparation for safety audits, and organization of safety meetings at the headquarters level.

The first group of comments concerned, the interviewees noticed that the organization did not have in place formal procedures for consistent safety data sharing across the various actors of safety management activities at the senior management level. More particularly, the procedures in place required the distribution of safety investigation across all sections and units of the organization and that special briefings should be scheduled for discussing the respective findings at the aforementioned 
functional levels; however, such a practice was not followed at the headquarters. Moreover, the dissemination of safety investigation reports across the various departments of each section was not formally required and it depended on the initiatives of safety staff. Therefore, safety committee members and safety auditors positioned at the senior and middle organizational levels had not been constantly exposed to such information, which, however, was widely shared with the operational level.

The two safety auditors interviewed noted that, in general, the quest for access to an investigation report was a matter of personal interest (e.g., they might had heard about an accident and they had looked for more information about it), a practice that was not consciously linked with their job roles although it was of added value for their knowledge. All participants recognised that, in addition to the inadequate communication of investigation reports, the organization lacked a common database for integrating the findings from audits, safety investigations and the rest of the safety management activities (e.g., voluntary reports, safety inspections and safety studies). Hence, the retrieval of inclusive safety data per point of interest or organizational function was not feasible.

The safety audits concerned, the respective interviewees referred to the respective organizational guidelines which required from auditors a preparation based principally on the findings of previous audits at the unit to be assessed and the consultation with the formal handbook which includes predefined check topics. Neither the aforementioned document prompted auditors to search for safety information from other sources, nor the need for such a research had been pointed during audit training. The interview participants recognised the importance of audits in identifying safety related weaknesses at units, where safety is operationalised, but they noticed that 
similar internal audits at the middle and senior management levels were not foreseen. This had deprived the organization from the opportunity to identify flaws at those levels and improve the coordination of safety management activities.

In response to a question regarding the causal factors not included in the audit check-list (i.e. Supervision, Domestic Object Debris and Depot Maintenance Act), the participants stated that the Supervision factor was not a topic of evaluation due to the predominant culture which favoured a focus on the end-products of operations, and consequently the work floor, rather on the effectiveness of supervision. Furthermore, although discussions with staff serving in a variety of positions at each unit were held during audits, the units' employees were concerned more about the support provided by the middle and senior management levels on reported problems rather about the effectiveness of management at the unit level.

The lack of dedicated audit topics about Domestic Object Debris was attributed to its coverage by the topics related to the Maintenance Personnel Act factor (e.g., on-job assessments and knowledge tests) and the audits performed by technical quality experts. The findings of airworthiness checks were communicated to safety personnel but not directly contemplated as safety concerns when corresponding remedies had been planned. Thus, a visible connection between airworthiness and safety was missing. The participants stated that although the audit of depot maintenance offered by contractors was outside the scope of unit audits, the organization had in place special procedures for the inspection, test and storage of systems and components received from contractors. The check for the adherence to those procedures was a responsibility of airworthiness related audit topics and, once more, not directly shared with safety auditors. 
The interview participants viewed safety review meetings as a determinative activity enabling all organizational levels to achieve a common understanding of the safety challenges and exchanging relevant information and perspectives. The comments of interviewees confirmed the lack of detailed procedures about the preparation of safety meetings at the senior and middle management levels, as this was observed during the course of this research when reading through the relevant documentation. The agenda of such meetings was compiled according to the suggestions of the participants and any major pending subjects that had been reported by sections and units. The persons who developed the meeting agenda did not structurally take into consideration the whole spectrum of available safety sources, because the respective organizational directive referred abstractly and only indicatively to the range of topics to be examined by safety committees. Consequently, the decision to address accident and incident factors during the review meetings was based on intuition and individual perceptions, whereas safety audit findings were not considered as agenda topics.

\section{Discussion}

\subsection{Analysis sub-questions}

The answers to the analysis questions set in Table 2 are presented below based on the results from the overall sample. In order to facilitate the discussion about each analysis question, the researcher in this section of the paper included tables with aggregated results from the data presented in Tables 4, $5 \& 6$. More specifically, the tables of this section report the differences of the ratios of each pair of data source presented in Table 2 .

"Have safety auditors focused on problems at the same frequency such problems were recorded in the safety investigation reports?” 
The qualitative evaluation of ratios (Table 7) suggest that safety audit findings differed from the frequencies of all 5 causal factors contributed to the accidents and incidents across all functional levels, such a gap indicating a misalignment between the focus of audits and the frequency of safety problems encountered at the operational level. Interestingly, the ratio differences are quite similar concerning the organization in overall and the specific section, a fact that indicates the same level of horizontal (mis)alignment. Ratio differences were higher at the unit level for the cases of unsafe acts, which were much unaddressed during audits, and bird strikes, which were assigned a relatively high importance by auditors. Nevertheless, regardless functional level, audits revealed problems related to the Aircrew acts, Maintenance personnel acts and Material failure factors with a lower frequency than such factors were involved into safety events, whereas auditors in general focused vastly on FOD related deficiencies.

\begin{tabular}{|l|c|c|c|}
\hline \multirow{2}{*}{\multicolumn{1}{c|}{ Causal Factors }} & \multicolumn{3}{c|}{ Ratio differences* } \\
& Organization & Section & Unit \\
\cline { 2 - 4 } & & & \\
\hline Aircrew act & +0.22 & +0.16 & +0.39 \\
\hline Bird strike & -0.05 & -0.10 & -0.56 \\
\hline Foreign Object Debris & -0.35 & -0.34 & -0.22 \\
\hline Maintenance personnel act & +0.13 & +0.12 & +0.28 \\
\hline Material failure & +0.43 & +0.47 & +0.28 \\
\hline * Excluding causal factors not assessed during safety audits \\
\hline
\end{tabular}

Table 7: Differences of Ratios: Investigation and Audit Reports

The interviews revealed that safety auditors were not formally guided by organizational procedures to consider findings of safety investigation reports regarding events occurred at each unit. When the reasons about the exclusion of three causal factors from safety audits were discussed, the interviewees communicated the prevalence of a culture pointing on the sharp-end and recognised a lack of coordination between safety and technical quality management. The former reason might explain the 
fact that the Supervision factor was not included in the audit handbook although it had contributed to a considerable amount of accidents and incidents, and the focus on the unsafe acts of end-users as observed in the discussion above about the ratio differences.

"Have safety committees proportionally discussed internal safety audit findings?"

According to the aggregated results shown in Table 8, there was a divergence amongst the two respective safety management activities. The comparison of the ratios between audit findings and safety meeting topics at the organization and section levels revealed that although the FOD factor was most frequently addressed by safety auditors, this factor was not proportionally discussed by safety committees. On the other hand, unsafe acts were attended by safety meeting participants at all organizational levels quite more frequently than they actually contributed to safety events. Also, although safety auditors at the unit level revealed many problems in the control of Bird Strike hazards, safety meetings did not include the respective topic.

\begin{tabular}{|l|c|c|c|}
\hline \multirow{2}{*}{\multicolumn{1}{c|}{ Causal Factors }} & \multicolumn{3}{c|}{$\begin{array}{c}\text { Ratio differences* } \\
\text { (Audit reports - Meeting minutes) }\end{array}$} \\
\cline { 2 - 4 } & Organization & Section & Unit \\
\hline Aircrew act & -0.17 & -0.13 & -0.18 \\
\hline Bird strike & +0.04 & -0.08 & +0.60 \\
\hline Foreign Object Debris & +0.45 & +0.30 & +0.09 \\
\hline Maintenance personnel act & -0.14 & -0.21 & -0.10 \\
\hline Material failure & +0.01 & -0.10 & -0.06 \\
\hline * Excluding causal factors not assessed during safety audits \\
\hline
\end{tabular}

Table 8: Differences of Ratios: Audit Reports and Meeting Minutes

The interviewees attributed the aforementioned gaps to the insufficiency of organizational procedures regarding the development of safety meeting agendas at the senior and middle management levels. However, albeit such detailed guidance was available at the unit level, still the corresponding safety committees had not evidently considered the findings of safety auditors. This remark denotes that the presence of 
formal procedures at the operational level did not suffice to activate the expected coordination between safety meeting planners and safety auditors and enable a joint approach to the unit's safety issues; this finding was aligned with the views of Heesen (2012) presented in the literature section. As commented in the previous analysis question, the exclusion of the Supervision causal factor from audit checks rather led to an overemphasis on the unsafe acts of operational staff.

"Have safety committees addressed causal factors at the same extent such factors were uncovered through safety investigations?”

When comparing the ratios of the causal factors published in the investigation reports with the ratios of those factors discussed in the safety meetings (Table 9), a variety of differences can be observed across all three organizational levels. The biggest differences at the headquarters level regarded the material failures, which were underrepresented in the safety meeting minutes, and the Supervision causal factor that was overrepresented in the minutes. Also, the FOD and DOD factors were discussed less frequently by the safety committees than they contributed to the safety events of the organization. At the section level, material failures and DOD cases were not included in the agenda topics at the frequency they were recorded in the investigation reports, whereas the Bird Strike factor was over-discussed during the safety meetings. The participants of the safety review meetings at the operational level paid a high attention to the FOD causal factor but they did not converse about the Aircrew and Material Failures proportionally to the extent those causes had contributed to the safety events of the specific unit. 


\begin{tabular}{|l|c|c|c|}
\hline \multirow{2}{*}{\multicolumn{1}{c|}{ Causal Factors }} & \multicolumn{3}{c|}{ Ratio differences } \\
& (Investigation reports - Meting minutes) \\
\cline { 2 - 4 } & Organization & Section & Unit \\
\hline Aircrew act & +0.05 & +0.03 & +0.21 \\
\hline Bird strike & -0.01 & -0.18 & +0.04 \\
\hline Domestic Object Debris & +0.10 & +0.14 & +0.06 \\
\hline Foreign Object Debris & +0.09 & -0.04 & -0.13 \\
\hline Maintenance personnel act & -0.01 & -0.09 & +0.18 \\
\hline Material failure & +0.42 & +0.37 & +0.22 \\
\hline Outsource-depot maintenance act & +0.05 & +0.04 & +0.06 \\
\hline Supervision factors & -0.38 & +0.03 & -0.02 \\
\hline
\end{tabular}

Table 9: Differences of Ratios: Investigation Reports and Meeting Minutes

The interview results suggest that the aforementioned inconsistencies were a product of the lack of directives for the organization of safety meetings at the headquarters level, as discussed for the previous analysis question. However, since the agenda items at the unit level were prescribed in the relevant documentation and dictated the requirement to discuss causal factors contributed to local safety events, the distance uncovered through the analysis and comparison of safety meeting minutes and investigation reports confirmed that the existence of procedures alone cannot guarantee alignment (Heesen, 2012). It seems that safety meeting participants at the unit level discussed findings of investigations based on individual perceptions of importance and not a consistent consideration of frequencies of the local accident and incident factors.

\subsection{Overarching question}

Regarding the overarching question of the study "To what degree do safety committees and auditors are aligned with each other and with the results from safety investigations?”, when considering collectively the results from the three analysis subquestions, a misalignment of the two core safety management activities (i.e. safety meetings and audits) between them and with the findings of safety investigations emerged. This was principally attributed to the lack of coherent communication among the safety staff participating in safety review meetings and performing safety audits and 
the lack of a procedure for considering the findings from safety investigations as part of the aforementioned management practices. Therefore, the safety management activities at the specific organization seemed inadequately coordinated although various authors cited in the literature review section above (i.e. section 2.1) have stressed the need for continuous interaction across safety actors and the recognition of interdependencies among safety management activities.

On one hand, the fact that the interviewees acknowledged the importance of safety meetings and audits for boosting the effectiveness of safety management confirmed the references of the literature discussing the significance of those two practices (section 2.2 above). On the other hand, an alignment-focused view of safety management, as suggested by the literature (sections $2.1 \& 2.3$ above), was not evident. Rather, safety meetings, audits and investigations were seen as individual tasks and their intersection was missing. Definitely, the lack of a central safety information database had played a role in the misalignment observed. Furthermore, the culture of the specific organization, which espoused an emphasis on problems at the operational level and end-users and excluded self-checks at the middle and senior management levels, was also deemed as influential.

Furthermore, the variations of the ratios over the 6 years' period across all organizational levels did not reveal any patterns that could indicate a consistent convergence or divergence of the three safety management activities over time. Some causal factors were rarely or not at all discussed during safety meetings and dealt by the auditors, or they were occasionally appearing and disappearing from the meeting minutes and audit reports. Due to time limitations, the erratic differences between the ratios of causal factors recorded in safety investigation reports, safety meeting minutes 
and audit reports were not presented to the interviewees; therefore, their explanation based on the insights of the organization's employees was not feasible. Nonetheless, the observation of the data in the Appendix does not provide any indications of possible delays of auditors or meeting attendants in addressing causes that affected safety performance of the organization. Such "planned" and "justified" delays could be claimed if the ratios of the causal factors found in meeting minutes and/or audit reports had been similar to the sum or average of such ratios referred in the investigation reports of the 2-3 preceding years.

Certainly, the frequency of findings stated in the audit reports might had been affected by the quality of the audits in terms of completeness and representativeness under the reality of limited time and resources. However, taking into account that an awareness of the auditors about the most important weaknesses of each unit, as those had been unveiled through safety investigations, would have led the auditors to search more intensively for flaws related to the respective causal factors (i.e. the more you search, the more you find), the validity of the results was not influenced by the quality of audits. Nevertheless, the quality of both the audit handbook and auditors' training were not examined in this study, but could have influenced the misalignment observed. Also, the author adapted the calendar year as the time unit of reference when calculating ratios; although the choice of different time intervals might lead to a different picture of a situation under study (Panagopoulos, Atkin, \& Sikora, 2016), this is not expected to have influenced the results of this research due to the high variance of data observed across the calendar years studied. 


\section{Conclusions}

Although safety concerned organizations might monitor the effective operation of their safety management and the levels of safety performance in order to allocate resources to the areas mostly affected, literature also suggests that it is essential to assess the alignment of safety management practices. The specific research assessed such an alignment under the concept that consistent discussions about the deficiencies revealed during audits, and coherent reviews of local and systemic causal factors formulated in investigation reports were expected to comprise discussion topics of the safety committees of the organization under study. Under the same logic, safety audits were expected to focus on weak areas identified during safety investigations.

The qualitative and quantitative analysis of data derived from safety investigation reports, meeting minutes and internal audit reports followed by their cross-reference demonstrated that auditors and safety committees across all three functional levels of the aviation organization under research had not proportionally focused on the prevalent accident and incident factors. Therefore, safety audits and meetings had not unfolded their full potential to arm the organization against the flaws uncovered by safety investigators. Also, there was a misalignment between the concerns of safety committees and the findings of safety auditors.

Interviews with safety professionals of the organization showed that the nonsharing of safety information across the whole organization, the lack of relevant procedures, a missing cross-check and self-check culture, mostly at the senior and middle management functions, an overemphasis on the end-user level, which was also reflected in the audit guidebook, and a gap between technical quality management and safety management hindered a focus on issues proportionate to the degree the latter had 
affected safety performance. Those findings were aligned with the factors mentioned by Heesen (2012), who, amongst others, advocated the role of information technology in successful vertical and horizontal alignment and the cascade of performance objectives across an organization. It is noted though that horizontal alignment was not recognised as an objective of the organization studied in this research. Additional collection and analysis of data from the rest of the middle sections and operating units as well as more interviews with safety and operational staff serving at the respective levels were proposed to the organization as a means to gain further insights and provide a complete picture regarding the factors undermining the alignment of safety management initiatives within the various organizational levels, the quality of audits included.

Content analysis of documented data, as followed in this research, might be time consuming. However, if organizations proceed to analysing initially an adequate sample of documents, the annual retrofit of the corresponding datasets and the recalculation of ratios might not require a plethora of resources. Based on the findings of such cross-reference studies, organizations might reform their procedures and infrastructure regarding data sharing and dissemination of safety critical information amongst staff who are assigned to perform various safety management activities (e.g., update of risk registry, amendment of safety training syllabus, preparation of safety meeting agenda items, planning of safety audits). Such findings might be used to probe discussions across the organization and provide the opportunity for collecting views about the implementation of safety management activities beyond prescribed procedures and monitoring of indicators linked to individual SMS processes.

Certainly, safety investigations, review meetings and audits are not the only safety management practices contributing to organizational sustainability. Safety 
training and education, risk management, safety assurance and other safety management activities must also be considered regarding their intersections and evaluation of the degree of their alignment through the cross-reference of relevant data. Hence, the technique presented in this study is not confined to the safety management activities considered for the scope of the specific research. Respective cross-reference studies may assist organizations in evaluating the extent of convergence of their various safety initiatives, and establishing relevant quantified objectives as a means to evaluate how effectively their safety management is implemented.

Moreover, it is underlined that the provision of quantified evidence about the association between the alignment of safety management activities and safety performance was not included in the objectives of this study. Further research is recommended in order to explore the linkage between safety performance and horizontal alignment of safety management practices and provide evidence about the merit of establishing respective Critical Success Factors or Key Performance Indicators. In addition to the calculation of ratios performed in the frame of this study, future research might consider the use of Euclidean distances (Deza \& Deza, 2016) suggested by Joshi, Kathuria \& Porth (2003) as a simple measure of alignment, or other appropriate methods.

Nevertheless, the misalignments revealed during this research triggered the organization under study to identify its weaknesses, which is an important step towards improvement even under a lack of scientific evidence about the linkage of alignment with performance. Moreover, according to literature, is expected that the transition from a singular approach, which emphasises on the effective implementation of individual safety initiatives, to a view that highlights their interconnectivity and interdependencies 
will benefit organizations in terms of a common picture and discussion basis regarding safety.

A shared and proportionate focus on safety might be claimed when individual safety management actors are effectively coordinated in order to manage the factors potentially threatening organizational integrity. The current study researched such an alignment within an aviation organization and comprises a contribution to the literature regarding the assessment of horizontal alignment of safety management activities. The technique introduced might serve as an alternative way for practitioners to evaluate the effective implementation of a safety management scheme by exploring the extent to which safety management practices share the same picture of safety challenges and enact in tandem.

\section{References}

Andrews, R., Boyne, G. A., Meier, K. J., O'Toole, L. J., \& Walker, R. M. (2012). VerticaL Strategic Alignment and Public Service Performance. Public Administration, 90, 77-98.

Arocena, P., \& Núñez, I. (2010). An Empirical Analysis of the Effectiveness of Occupational Health and Safety Management Systems in SMEs. International Small Business Journal, 28, 398-420.

Bhagwati, K. (2006). Managing Safety. NJ: Wiley - VCH.

BSI. (2007). Occupational Health and Safety Management Systems - Requirements. BS OHSAS 18001:2007. UK: BSI British Standards.

Channing, J. E. (2008a). Risk Management: Organization \& Administration for Safety. In J. Channing, \& J. Ridley, Safety at Work. UK: Butterworth Heinemann.

Channing, J. E. (2008b). An Introduction to Risk Management. In J. Channing, \& J. Ridley, Safety at Work. UK: Butterworth - Heinemann.

Della - Giustina, D. (2007). Safety \& Environmental Management. UK: Scarecrow Press.

Deza, M. M., \& Deza, E. (2016). Encyclopedia of Distances (4th ed.). Berlin: Springer.

EASA. (2014). A Harmonised European Approach to a Performance Based Environment. Cologne: European Aviation Safety Agency.

EASA. (2016). Annual Safety Review. Cologne: European Aviation Safety Agency. Eurocontrol. (2012). Effectiveness of Safety Management. Brussels: Eurocontrol. FAA. (2006). Introduction to Safety Management Systems for Air Operators. Advisory Circular 120-92. USA: Federal Aviation Administration. 
Ferrett, E., \& Hughes, P. (2007). Introduction to Health \& Safety in Construction (2nd ed.). UK: Butterworth - Heinemann.

Gibson, C. B., \& Birkinshaw, J. (2004). The Antecedents, Consequences, and Mediating Role of Organizational Ambidexterity. The Academy of Management Journal, 47(2), 209-226.

Goglia, J., Halford, C. D., \& Stolzer, A. J. (2008). Safety Management Systems in Aviation. UK: Ashgate.

Hanson, J. D., Melnyk, S. A., \& Calantone, R. A. (2011). Defining and measuring alignment in performance management. International Journal of Operations \& Production Management, 31(10), 1089-1114.

Heesen, B. (2012). The Strategic Alignment Process. In B. Heesen, Effective Strategy Execution, Management for Professionals (pp. 21-44). Verlag: Springer.

Hofmann, D. A., Jacobs, R., \& Landy, F. (1995). High Reliability Process Industries: Individual, Micro, and Macro Organizational Influences on Safety Performance. Journal of Safety Research, 26(3), 131-149.

HSE. (2013). Managing for Health and Safety. HSG65, 3rd. UK: Health and Safety Executive.

Hughes, L., \& Hughes, P. (2008). Easy Guide to Health \& Safety. UK: Butterworth Heinemann.

IAEA. (2006). Application of the Management System for Facilities and Activities. Safety Guide GS-G-3.1. Vienna: International Atomic Energy Agency.

IAEA. (2015). Annual Report 2014. Vienna: International Atomic Energy Agency.

IATA. (2014). Safety Report 2013. CA: International Air Transport Association.

IBM. (2013). IBM SPSS Statistics for Windows version 22. Armonk, NY: IBM Corp.

ICAO. (2013). Safety Management Manual. Doc. 9859. Canada: International Civil Aviation Organization.

ICAO. (2016a). Safety Management. Annex 19 to the Convention of International Civil Aviation. Montreal: International Civil Aviation Organization.

ICAO. (2016b). Safety Report. CA: International Civil Aviation Organization.

IIA. (2009, January). The Role of Internal Auditing in Enterprise-wide Risk

Management. London: The Institute of Internal Auditors. Retrieved from https://na.theiia.org/standards-guidance/

IIA. (2012, December). What is Internal Audit? London: Chartered Institue of Internal Auditors. Retrieved from https://www.iia.org.uk/media/91287/0731_what_is_internal_audit_dec_2012.p df

ILO. (2001). Guidelines on Occupational Safety and Health Management Systems. ILO-OSH 2001. Geneva: International Labour Office.

IOGP. (2014). Operating Management System Framework. London: International Association of Oil \& Gas Producers.

IOGP. (2015). Safety Performance Indicators. London: International Association of Oil \& Gas Producers.

Joshi, M. P., Kathuria, R., \& Porth, S. J. (2003). Alignment of strategic priorities and performance: an integration of operations and strategic management perspectives. Journal of Operations Management, 21, 353-369.

Karanikas, N. (2014a). An Organizational Structure Based on Risk and Quality Fundamentals. MERC's Global International Journal of Management, 2(1), 119. 
Karanikas, N. (2014b). A Comprehensive Contemporary Safety Management Systems Framework Including Planning and Monitoring Guidance. MERC's Global International Journal of Management, 2(3), 69-96.

Karanikas, N. (2016a). Combining Soft System Methodology and Pareto Analysis in the Assessment of Safety Management Performance: an Aviation Case. International Journal of Business Performance Management, 17(3), 286-300.

Karanikas, N. (2016b). Critical Review of Safety Performance Metrics. International Journal of Business Performance Management, 17(3), 266-285.

Kaspers, S., Karanikas, N., Roelen, A. L., Piric, S., \& de Boer, R. J. (2016a). Review of Existing Aviation Safety Metrics. Aviation Academy. Amsterdam: Amsterdam University of Applied Sciences.

Kaspers, S., Karanikas, N., Roelen, A., Piric, S., van Aalst, R., \& de Boer, R. J. (2016b). Results from Surveys about Existing Aviation Safety Metrics. Amsterdam: Aviation Academy, Amsterdam University of Applied Sciences.

Kathuria, R., Joshi, M. P., \& Porth, S. J. (2007). Organizational alignment and performance: past, present and future. Management Decision, 45(3), 503-517.

Kemp, S. (2006). Quality Management Demystified. NY: McGraw-Hill.

Leveson, N. (2004). A New Accident Model for Engineering Safer Systems. Safety Science, 42(4), 237-270.

Leveson, N. (2011). Engineering a Safer World: Systems Thinking Applied to Safety. Cambridge, MA, USA: MIT Press.

Manuele, F. A. (2008). Advanced Safety Management Focusing on Z10 \& Serious Injury Prevention. NJ: John Wiley \& Sons.

Mearns, K., Whitaker, S. M., \& Flin, R. (2003). Safety Climate, Safety Management Practice and Safety Performance in Offshore Environments. Safety Science, 41, 641-680.

Nga, S. T., Chenga, K. P., \& Skitmoreb, R. M. (2005). A Framework for Evaluating the Safety Performance of Construction Contractors. Building and Environment, 40, 1347-1355.

Panagopoulos, I., Atkin, C., \& Sikora, I. (2016). Lean Six-Sigma in Aviation Safety: An implementation guide for measuring aviation system's safety performance. International Cross-industry Safety Conference (pp. 30-43). Journal of Safety Studies 2(2).

Pidgeon, N. F. (1991). Safety Culture and Risk Management in Organizations. Journal of Cross-Cultural Psychology, 22(1), 129-140.

Powell, T. C. (1992). Organizational Alignment as Competitive Advantage. Strategic Management Journal, 13, 119-134.

Ridley, J. R. (2008). Health \& Safety in Brief. UK: Butterworth - Heinemann.

Robson, L. S., Clarke, J. A., Cullen, K., Bielecky, A., Severin, C., Bigelow, P. L., . . . Mahood, Q. (2007). The Effectiveness of Occupational Health and Safety Management System Interventions: A Systematic Review. Safety Science, 45, 329-353.

Ruud, T. F. (2003). The Internal Audit Function: An Integral Part of Organizational Governance. In A. Gramling, \& S. Ramamoorti, Research Opportunities in Internal Auditing (pp. 73-96). Florida: The Institute of Internal Auditors Research Foundation, Altamonte Springs.

Salimian, H., Khalili, S., Nazemi, J., \& Alborzi, M. (2012). Alignment in the organization's strategy window. African Journal of Business Management, 6(51), 12016-12022. 
Simons, N. (2014). A Framework for Organizational Alignment. Novi, Michigan: Performance Innovation LLC.

SMICG. (2012). Safety Management System Evaluation Tool. Safety Management International Collaboration Group.

Stapenhurst, T. (2009). The Benchmarking Book: A How-to-Guide to best Practice for Managers \& Practitioners. UK: Elsevier.

Tam, C., \& Fung, I. W. (1998). Effectiveness of Safety Management Strategies on Safety Performance in Hong Kong. Construction Management and Economics, 16(1), 49-55.

Thomas, M. (2012). A Systematic Review of the Effectiveness of Safety Management Systems. Australia: Australian Transport Safety Bureau.

Vredenburgh, A. G. (2002). Organizational Safety: Which Management Practices Are Most Effective in Reducing Employee Injury Rates. Journal of Safety

Research, 33, 259- 276. 


\section{Appendix}

\begin{tabular}{|c|c|c|c|c|c|c|c|c|c|c|c|c|c|c|c|c|c|c|}
\hline \multirow{3}{*}{ Causal Factors } & \multicolumn{18}{|c|}{ Average Ratios per Year (I: Investigations, A: Audits, M: Meetings) } \\
\hline & \multicolumn{3}{|c|}{ Year 1} & \multicolumn{3}{|c|}{ Year 2} & \multicolumn{3}{|c|}{ Year 3} & \multicolumn{3}{|c|}{ Year 4} & \multicolumn{3}{|c|}{ Year 5} & \multicolumn{3}{|c|}{ Year 6} \\
\hline & $\mathbf{I}$ & $\mathbf{A}$ & $\mathbf{M}$ & $\mathbf{I}$ & $\mathbf{A}$ & $\mathbf{M}$ & $\mathbf{I}$ & $\mathbf{A}$ & $\mathbf{M}$ & $\mathbf{I}$ & $\mathbf{A}$ & $\mathbf{M}$ & I & $\mathbf{A}$ & $\mathbf{M}$ & $\mathbf{I}$ & $\mathbf{A}$ & $\mathbf{M}$ \\
\hline Aircrew act & 0.18 & 0.00 & 0.22 & 0.29 & 0.00 & 0.00 & 0.19 & 0.00 & 0.00 & 0.16 & 0.00 & 0.08 & 0.24 & 0.00 & 0.00 & 0.39 & 0.00 & 0.50 \\
\hline Bird strike & 0.08 & 0.30 & 0.00 & 0.08 & 0.24 & 0.00 & 0.09 & 0.04 & 0.33 & 0.11 & 0.00 & 0.08 & 0.08 & 0.00 & 0.00 & 0.17 & 0.20 & 0.25 \\
\hline $\begin{array}{l}\text { Domestic Object } \\
\text { Debris }\end{array}$ & 0.09 & $*$ & 0.00 & 0.01 & $*$ & 0.00 & 0.19 & $*$ & 0.00 & 0.11 & $*$ & 0.00 & 0.20 & $*$ & 0.00 & 0.00 & * & 0.00 \\
\hline $\begin{array}{l}\text { Foreign Object } \\
\text { Debris }\end{array}$ & 0.19 & 0.37 & 0.04 & 0.15 & 0.40 & 0.00 & 0.13 & 0.81 & 0.00 & 0.06 & 0.50 & 0.08 & 0.08 & 0.38 & 0.00 & 0.22 & 0.40 & 0.00 \\
\hline $\begin{array}{l}\text { Maintenance } \\
\text { personnel act }\end{array}$ & 0.19 & 0.00 & 0.19 & 0.13 & 0.00 & 0.00 & 0.08 & 0.00 & 0.33 & 0.13 & 0.00 & 0.08 & 0.08 & 0.00 & 0.00 & 0.11 & 0.00 & 0.00 \\
\hline Material failure & 0.41 & 0.00 & 0.06 & 0.45 & 0.02 & 0.00 & 0.47 & 0.04 & 0.00 & 0.53 & 0.00 & 0.00 & 0.40 & 0.00 & 0.00 & 0.28 & 0.00 & 0.00 \\
\hline $\begin{array}{l}\text { Outsource-depot } \\
\text { maintenance act }\end{array}$ & 0.07 & $*$ & 0.06 & 0.05 & $*$ & 0.00 & 0.11 & $*$ & 0.00 & 0.06 & $*$ & 0.00 & 0.08 & $*$ & 0.00 & 0.06 & * & 0.00 \\
\hline Supervision factors & 0.06 & $*$ & 0.43 & 0.08 & $*$ & 0.00 & 0.16 & $*$ & 0.33 & 0.11 & $*$ & 0.67 & 0.28 & * & 0.00 & 0.33 & * & 0.25 \\
\hline
\end{tabular}

* Not assessed during safety audits

Table A.1: Results per Year for the Organization 


\begin{tabular}{|c|c|c|c|c|c|c|c|c|c|c|c|c|c|c|c|c|c|c|}
\hline \multirow{3}{*}{ Causal Factors } & \multicolumn{18}{|c|}{ Average Ratios per Year (I: Investigations, A: Audits, M: Meetings) } \\
\hline & \multicolumn{3}{|c|}{ Year 1} & \multicolumn{3}{|c|}{ Year 2} & \multicolumn{3}{|c|}{ Year 3} & \multicolumn{3}{|c|}{ Year 4} & \multicolumn{3}{|c|}{ Year 5} & \multicolumn{3}{|c|}{ Year 6} \\
\hline & $\mathbf{I}$ & $\mathbf{A}$ & M & $\mathbf{I}$ & $\mathbf{A}$ & M & $\mathbf{I}$ & $\mathbf{A}$ & $\mathbf{M}$ & $\mathbf{I}$ & $\mathbf{A}$ & $\mathbf{M}$ & $\mathbf{I}$ & $\mathbf{A}$ & $\mathbf{M}$ & $\mathbf{I}$ & A & $\mathbf{M}$ \\
\hline Aircrew act & 0.14 & 0.00 & 0.25 & 0.19 & 0.00 & 0.00 & 0.12 & 0.00 & 0.00 & 0.09 & 0.00 & 0.20 & 0.21 & 0.00 & 0.00 & 0.33 & 0.00 & 0.33 \\
\hline Bird strike & 0.16 & 0.44 & 0.00 & 0.08 & 0.17 & 0.00 & 0.12 & 0.07 & 0.00 & 0.03 & 0.00 & 0.40 & 0.07 & 0.00 & 0.50 & 0.25 & 0.33 & 0.33 \\
\hline $\begin{array}{l}\text { Domestic Object } \\
\text { Debris }\end{array}$ & 0.12 & $*$ & 0.00 & 0.00 & $*$ & 0.00 & 0.27 & $*$ & 0.00 & 0.19 & $*$ & 0.00 & 0.21 & $*$ & 0.00 & 0.00 & * & 0.00 \\
\hline $\begin{array}{l}\text { Foreign Object } \\
\text { Debris }\end{array}$ & 0.22 & 0.22 & 0.25 & 0.17 & 0.50 & 0.00 & 0.12 & 0.87 & 0.00 & 0.03 & 0.00 & 0.00 & 0.07 & 0.50 & 0.25 & 0.17 & 0.33 & 0.33 \\
\hline $\begin{array}{l}\text { Maintenance } \\
\text { personnel act }\end{array}$ & 0.18 & 0.00 & 0.25 & 0.06 & 0.00 & 0.00 & 0.03 & 0.00 & 1.00 & 0.19 & 0.00 & 0.00 & 0.14 & 0.00 & 0.00 & 0.08 & 0.00 & 0.00 \\
\hline Material failure & 0.31 & 0.00 & 0.00 & 0.58 & 0.00 & 0.00 & 0.58 & 0.07 & 0.00 & 0.72 & 0.00 & 0.20 & 0.36 & 0.00 & 0.25 & 0.25 & 0.00 & 0.00 \\
\hline $\begin{array}{l}\text { Outsource-depot } \\
\text { maintenance act }\end{array}$ & 0.04 & * & 0.00 & 0.03 & $*$ & 0.00 & 0.03 & * & 0.00 & 0.09 & $*$ & 0.00 & 0.00 & $*$ & 0.00 & 0.00 & * & 0.00 \\
\hline Supervision factors & 0.08 & $*$ & 0.25 & 0.05 & $*$ & 0.00 & 0.12 & $*$ & 0.00 & 0.09 & $*$ & 0.20 & 0.21 & $*$ & 0.00 & 0.25 & $*$ & 0.00 \\
\hline
\end{tabular}

Table A.2: Results per Year for the Section 


\begin{tabular}{|c|c|c|c|c|c|c|c|c|c|c|c|c|c|c|c|c|c|c|}
\hline \multirow{3}{*}{ Causal Factors } & \multicolumn{18}{|c|}{ Average Ratios per Year (I: Investigations, A: Audits, M: Meetings) } \\
\hline & \multicolumn{3}{|c|}{ Year 1} & \multicolumn{3}{|c|}{ Year 2} & \multicolumn{3}{|c|}{ Year 3} & \multicolumn{3}{|c|}{ Year 4} & \multicolumn{3}{|c|}{ Year 5} & \multicolumn{3}{|c|}{ Year 6} \\
\hline & $\mathbf{I}$ & $\mathbf{A}$ & $\mathbf{M}$ & $\mathbf{I}$ & $\mathbf{A}$ & $\mathbf{M}$ & $\mathbf{I}$ & $\mathbf{A}$ & $\mathbf{M}$ & $\mathbf{I}$ & $\mathbf{A}$ & $\mathbf{M}$ & $\mathbf{I}$ & $\mathbf{A}$ & $\mathbf{M}$ & $\mathbf{I}$ & A & $\mathbf{M}$ \\
\hline Aircrew act & 0.67 & 0.00 & 0.00 & 0.50 & 0.00 & 0.00 & 0.00 & 0.00 & 0.17 & 0.33 & 0.00 & 0.31 & 0.33 & 0.00 & 0.27 & 0.00 & 0.00 & 0.33 \\
\hline Bird strike & 0.00 & 1.00 & 0.00 & 0.17 & 0.00 & 0.08 & 0.00 & 0.00 & 0.05 & 0.00 & 0.00 & 0.00 & 0.33 & 0.00 & 0.00 & 0.00 & 1.00 & 0.21 \\
\hline $\begin{array}{l}\text { Domestic Object } \\
\text { Debris }\end{array}$ & 0.00 & $*$ & 0.00 & 0.00 & $*$ & 0.00 & 0.50 & $*$ & 0.00 & 0.00 & $*$ & 0.00 & 0.00 & $*$ & 0.00 & 0.00 & $*$ & 0.00 \\
\hline $\begin{array}{l}\text { Foreign Object } \\
\text { Debris }\end{array}$ & 0.33 & 0.00 & 0.25 & 0.00 & 0.00 & 0.46 & 0.00 & 1.00 & 0.06 & 0.00 & 0.00 & 0.08 & 0.00 & 0.00 & 0.20 & 1.00 & 0.00 & 0.29 \\
\hline $\begin{array}{l}\text { Maintenance } \\
\text { personnel act }\end{array}$ & 0.33 & 0.00 & 0.00 & 0.00 & 0.00 & 0.00 & 0.00 & 0.00 & 0.17 & 0.67 & 0.00 & 0.31 & 0.33 & 0.00 & 0.27 & 1.00 & 0.00 & 0.00 \\
\hline Material failure & 0.00 & 0.00 & 0.00 & 0.50 & 0.00 & 0.00 & 0.50 & 0.00 & 0.39 & 0.33 & 0.00 & 0.00 & 0.00 & 0.00 & 0.00 & 0.00 & 0.00 & 0.00 \\
\hline $\begin{array}{l}\text { Outsource-depot } \\
\text { maintenance act }\end{array}$ & 0.00 & $*$ & 0.00 & 0.00 & $*$ & 0.00 & 0.50 & $*$ & 0.00 & 0.00 & $*$ & 0.00 & 0.00 & $*$ & 0.00 & 0.00 & $*$ & 0.00 \\
\hline Supervision factors & 0.33 & $*$ & 0.50 & 0.00 & $*$ & 0.46 & 0.00 & $*$ & 0.17 & 0.67 & $*$ & 0.31 & 0.33 & $*$ & 0.27 & 1.00 & $*$ & 0.07 \\
\hline
\end{tabular}

Table A 3: Results per Year for the Unit 